\title{
Randomized controlled trial of exercise interventions for chronic whiplash-associated disorders: One-year follow-up of the effect on neck muscle endurance, active cervical range of motion and grip strength.
}

Gunnel Peterson ( $\sim$ gunnel.peterson@liu.se )

Linkopings universitet Medicinska Fakulteten https://orcid.org/0000-0003-2492-0306

Maria Landén Ludvigsson

Department of Health, Medicine and Caring Science, Linköping University

Anneli Peolsson

Department of Health Medicin and Caring Science

Research article

Keywords: exercise therapy, neck, spine, whiplash injuries

Posted Date: July 1st, 2020

DOI: https://doi.org/10.21203/rs.3.rs-35272/v1

License: (c) (i) This work is licensed under a Creative Commons Attribution 4.0 International License. Read Full License 


\section{Abstract}

Background: Years after whiplash injury, more than $40 \%$ of people experience persistent neck pain and disability, called whiplash-associated disorders (WAD). The relations between neck related function, neck pain and disability are inconclusive and need to be further investigated. The aims were; a) to compare the effect of three different exercise interventions - neck-specific exercise (NSE), NSE with a behavioral approach (NSEB) and prescribed physical activity (PPA) - on neck-muscle endurance (NME), active cervical range of motion (AROM), grip strength and pain intensity immediately before and after the tests, and b) to compare neck-disability in individuals who are below or above the cut-off for normative reference values of healthy individuals regarding NME, AROM and grip strength.

Methods: This is a secondary analysis of a randomized controlled multicenter study including 12 months' follow-up. A total of 216 individuals with chronic WAD grades II or III were recruited. Data were recorded at baseline, 3, 6, and 12 months. Linear mixed models were used and sub-group analyses were evaluated with non-parametric tests.

Results: NSE and NSEB resulted in greater improvements compared to PPA $(p<.01)$ and were maintained at 12 months' follow-up in ventral (only males) and dorsal NME, AROM and pain intensity during testing. In grip strength, there were no significant between-group differences ( $p>0.05$ ). There were no significant differences between the NSE and NSEB groups ( $p>05)$. Sub-group analyses revealed improvement in disability at 12 months follow-up in NSE and/or NSEB for individuals both below and above the cut-off reference value in NME and AROM. More severe disability was seen in individuals below the reference values both at baseline and 12 months' follow-up. Individuals in the PPA group below the reference values in NME and AROM reported increasing disability at 12 months compared to baseline.

Conclusion: The results suggest that neck-specific exercises (NSE, NSEB) improved clinical function and decreased disability in chronic WAD compared to PPA. The results may imply that higher neck-related clinical function can be important for reduced disability.

Trial Registration: ClinicalTrials.gov: NCT01528579, date of registration: February 8, 2012, retrospectively registered; https://clinicaltrials.gov/ct2/show/NCT0152857

\section{Background}

Years after a whiplash injury, more than $40 \%$ of patients experience persistent neck pain, disability, dizziness and other symptoms known as whiplash-associated disorders (WAD) (1-3). The injury and pain cause an altered function in the cervical spine and neck muscles (4-8) and can affect upper limb function (9-11). Self-reported pain and neck-related disability which affect personal care, lifting, reading, work, driving, and recreation can predict recovery after whiplash injury (12), but the relations between physical capacity and neck pain and disability are inconclusive $(13,14)$. Improved neck muscle endurance was an important factor in decreasing neck pain in WAD (15). Decreased cervical range of motion can affect daily activities, for example can skill driving be restricted by less than $40^{\circ}$ cervical rotation (16). In healthy adults, low grip strength were associated with risk of all-cause mortality and low cardiovascular fitness (17-19) and males with low grip strength in adolescence were at an increased risk of obtaining the disability pension (20).

In chronic WAD with arm- and neck pain, it can be speculated that decreased neck muscle function and cervical range of motion may lead to lower physical activity and thereby to general lower muscular strength and lower cardiovascular fitness. Exercises to improve function are important after whiplash injury and is recommended in combination with education as the primary intervention in chronic WAD (21). Randomized controlled exercise studies have reported, at best, modest evidence for improvements in chronic WAD (22-24). Neck-specific exercises, previously reported by our research group, led to reduced disability and pain one year after intervention (25), as reported in a questionnaire. Improvement in neck muscle endurance (NME) was also seen at 6 months' follow-up (26). The long-term effect of neck-specific exercises on NME at 12 months' follow-up has not been investigated nor has active cervical range of motion (AROM) or grip strength. Measurement of pain during testing may give information as to whether potentially improved physical function (NME, AROM and grip strength) also leads to less pain provocation. Moreover, to compare selfreported disability in individuals below against in line or above cut-off reference values for NME, AROM and grip strength in the three different exercise interventions (NSE, NSEB and PPA) can lead to enhanced understanding and improved exercise interventions for chronic WAD. We hypothesized that neck-specific exercise would have a positive effect on the deep and superficial neck muscles to control intersegmental motion and improve NME. We also hypothesized there would be some secondary effects of exercise on AROM and grip strength due to improved NME and decreased pain, which would thereby create an opportunity to decrease disability.

The aims of the present study were to evaluate neck-related clinical function and the relation to self-reported disability in chronic WAD as follows: a) compare the effect of three different exercise interventions - neck-specific exercise (NSE), neck-specific exercise with a behavioral approach (NSEB) and prescribed physical activity (PPA) - on NME, AROM, grip strength and pain intensity before and after the tests, and b) to compare self-reported neck-disability in individuals who are below against in line with or above the cut-off for normative reference values of healthy individuals regarding NME, AROM and grip strength.

\section{Methods}


This planned secondary analyses of NME, AROM and grip strength included participants in a prospective randomized controlled (RCT) multi-center study (ClinicalTrials.gov: NCT01528579), with assessor and group allocation blinding and included a 12 months' follow-up. This research is reported according to the CONSORT guidelines (27).

\section{Participants}

In this study 216 participants were included, 142 females and 74 males (mean age 40 years; SD, 11.4), of whom 123 had WAD grade II (neck pain and musculoskeletal signs) and 93 had grade III (neck pain plus neurological signs) (28). The flow diagram shows details of participants, recruitment and retention (Fig. 1). The recruitment of participants and the exercise interventions were reported earlier (26) and are briefly described below. Inclusion criteria were: neck symptoms associated with a whiplash injury at least 6 months but not more than 3 years prior to study entry, age between 18 and 63 years, WAD grade II or III, an average neck pain intensity over the past week $>20$ mm according to a 100-mm Visual Analog Scale (VAS), and/or > 20 on the Neck Disability Index (NDI, 0-100). Exclusion criteria were: signs of traumatic brain injury at the time of whiplash injury (disorientation, confusion, loss of consciousness, retrograde and posttraumatic amnesia), previous serious neck pain causing sick leave of more than 1 month during the 12-month period before their whiplash injury, inability to understand and write in Swedish, previous serious neck trauma/injury, neuromuscular or rheumatic disease, severe mental illness, current alcohol or drug abuse, or any condition that was contraindicated for exercise intervention.

\section{Procedure}

The participants were recruited between February 2011 and May 2012. Participants were identified from the healthcare registries of six Swedish counties, including primary healthcare centers and hospital outpatient services. Baseline data (Table 1) were collected, and experienced test leaders examined the participants before allocation. The test leaders were educated by the research team and followed a strict test protocol. The participants were randomized to one of three different exercise interventions by an independent researcher using a computer-generated list created by a University statistician. The independent researcher put the individual results in sealed opaque envelopes for further distribution to the treating physiotherapists. The test leaders were blinded to the participants' intervention group allocation and were not involved in delivering the interventions to participants. 
Table 1

Baseline characteristics of the three intervention groups: neck-specific exercise (NSE), neck-specific exercise with a behavioral approach (NSEB) and prescribed physical activity (PPA).

\begin{tabular}{|c|c|c|c|c|}
\hline Variables & NSE group $(N=76)$ & NSEB group $(N=71)$ & PPA group $(N=69)$ & P-value \\
\hline \multicolumn{5}{|l|}{ Variables mean (SD) } \\
\hline Age, (years) & $38.1(11.3)$ & $40.1(11)$ & 42.9 (10.7) & .03 \\
\hline BMI kg/m2 & $25.7(4.0)$ & $25.9(5.1)$ & $26.7(4.9)$ & .10 \\
\hline Injury duration ${ }^{a}$ & $19.1(8.5)$ & $20.3(8.9)$ & $19.6(9.7)$ & .69 \\
\hline \multicolumn{5}{|l|}{ Variables n (\% group) } \\
\hline $\mathrm{n}(\%)$ female & $57(75 \%)$ & $47(66 \%)$ & $38(55 \%)$ & .04 \\
\hline Sick-leave & $12(16 \%)$ & $19(27 \%)$ & $16(23 \%)$ & .27 \\
\hline Whiplash motor ${ }^{b}$ & $65(86 \%)$ & $54(76 \%)$ & $54(82 \%)$ & .29 \\
\hline Whiplash other ${ }^{\mathrm{c}}$ & $11(14 \%)$ & $17(24 \%)$ & $12(14 \%)$ & .29 \\
\hline WAD grade II & $49(64 \%)$ & $33(46 \%)$ & $41(59 \%)$ & .08 \\
\hline WAD grade III & $27(36 \%)$ & $38(54 \%)$ & $28(41 \%)$ & .08 \\
\hline Previous treatment $^{d}$ & $64(85 \%)$ & $57(80 \%)$ & $53(78 \%)$ & .37 \\
\hline Work full-time & $43(56 \%)$ & $36(51 \%)$ & $37(54 \%)$ & .72 \\
\hline Pain drugs ${ }^{\mathrm{e}}$ & $40(53 \%)$ & $44(62 \%)$ & $45(67 \%)$ & .09 \\
\hline \multicolumn{5}{|c|}{$\begin{array}{l}\text { BMI, body mass index; SD, standard deviation; WAD, whiplash-associated disorder; NDI, neck-disability index; NME, neck muscle endurance; } \\
\text { CROM, cervical range of motion }\end{array}$} \\
\hline \multicolumn{5}{|c|}{ a Months since whiplash injury. } \\
\hline \multicolumn{5}{|c|}{ bWhiplash injury as a result of a motor vehicle accident. } \\
\hline \multicolumn{5}{|c|}{ 'Whiplash injury due to other accidents (eg, fall, skiing, and diving). } \\
\hline \multicolumn{5}{|c|}{${ }^{\mathrm{d}}$ Sought health care (physician, physiotherapist) for neck pain after the whiplash injury, before entry in the study. } \\
\hline
\end{tabular}

\section{Interventions}

The exercise interventions were described in the study protocol (29) and will only be reported briefly below. The study interventions were delivered by physiotherapists practicing in primary health care. The physiotherapists received a day of standardized theoretical and practical training from the research team prior to study commencement. All three exercise interventions were undertaken over a 12-week period and the participants were encouraged to continue the exercises outside the physiotherapy clinic after completion of the intervention period.

\section{Neck-specific exercise (NSE)}

The exercises initially had a low load and targeted the deeper neck muscle layers. Neck-specific exercise (NSE) was supervised by a physiotherapist twice weekly during the 12 weeks, with additional home exercises. Participants in the NSE group were instructed to avoid pain aggravation during exercise and the exercises were continually progressed within each participant's symptom tolerance. The exercises continued with progressive low load resistance training with use of weighted pulleys and guild boards. The exercise program can be found at the Academic Archive On-line (30).

\section{Neck-specific exercise with a behavioral approach (NSEB)}

Exercises were identical to those performed by the NSE group with the addition of a brief behavioral intervention based on social cognitive theory and the transtheoretical model (31). The behavioral intervention including education and strategies for pain management (e.g. relaxation, dealing with neck pain relapse). In contrast to the NSE group, participants in the NSEB group were encouraged to continue their exercises and activities despite pain, but to avoid a cumulative elevation of pain intensity over time.

Prescribed physical activity (PPA) 
The PPA group had one or two appointments with the physiotherapist and the participants were prescribed an individual physical activity program (e.g. general aerobic exercises, gym classes). The program did not include neck-specific exercises and activity was performed outside the health care system. The participants could phone the physiotherapist if they wished to ask questions during the 12 weeks.

\section{Outcome measurements}

All measurements (clinical and questionnaires) were conducted at baseline, 3, 6 and 12 months after baseline. NME and pain intensity before and after the tests have been reported for 3 and 6 months outcome (26), therefore only results of changes from baseline to 12 months will be presented in NME. For AROM and grip strength, all time points will be presented. Well-trained test leaders performed the clinical tests in a standardized way. The investigators were blinded to the randomization procedure and were not involved in providing the exercise interventions. Before each test, the measurement process was explained to participants.

\section{Neck Muscle Endurance (NME)}

NME has good reliability (intra-class correlation coefficient, ICC 0.88-0.93) (32). NME was standardized and measured in seconds as previously described $(26,33)$. Ventral NME was tested first with the patient supine, positioned with straight legs, arms alongside the body, and head and cervical spine in a neutral position. The participants were given instructions to nod slightly, retract their chin, and raise their head just above the examination table. The participants practiced the test once in supine (with a slight nod, retracting the chin but not lifting the head) before the test started. Directly after the ventral NME test was the dorsal NME test. Dorsal NME was measured with the patient prone, positioned with straight legs, arms alongside the body, and head initially supported on the examination table. A load of $2 \mathrm{~kg}$ for females and $4 \mathrm{~kg}$ for males was applied to the head and the participants were instructed to lift their head just above the examination table. The tip of the chin should point at the floor, thus performing a slight extension of the cervical spine. The dorsal NME was practiced once in prone (chin pointing at floor and head lifting without the weight) before the real test started. The test position should be maintained for as long as possible. The participants were asked to stop the test by returning the head to rest at the point of neck fatigue and in case of radiating pain into the arm or severe neck pain. The test position was corrected by the test leader if necessary. NME was measured in seconds using a stopwatch. The test was stopped if the participants were unable to hold the test position.

\section{Active Range of Motion (AROM)}

AROM was assessed in sagittal (flexion/extension), frontal (lateral flexion), and transverse (rotation) planes with a Cervical Range of Motion Device (CROM) showing substantial reliability (ICC range .77 to .99) (34). The participants were sitting upright with neutral pelvic position, hips and knees at $90^{\circ}$ and arms resting in the lap. The CROM device was placed on their head. The participants were told to move their head at a steady pace as far as possible, keeping the body and shoulders still. The test leader held their hands on the participants' shoulders to minimize movements in body and shoulders. All measurements were taken in the same order, flexion, extension, right and then left lateral flexion followed by right and left rotation. The participant took a pause at the end of each movement so readings could be taken and then they returned to the neutral position before the next movement.

\section{Grip strength}

Isometric hand grip strength was measured with the Jamar Hand Dynamometer which is a reliable method (intra-class correlation coefficient, ICC .85 to .98) (35). Handgrip strength was measured once on the right and once on the left hand with participants standing, arms alongside the body with the elbows at $90^{\circ}$, the forearms in a neutral position and $0^{\circ}$ wrist extension. Maximum strength was assessed in kilograms after 6 seconds of sustained maximal contraction.

\section{Pain}

Pain intensity of the neck was measured using the Visually Analogue Scale (VAS) with a scale of 0 mm (no pain) to 100 mm (worst imaginable pain) immediately before and after the tests (36).

\section{Self-reported neck disability}

Disability was measured with the Neck Disability Index (NDI) which consists of 10 items (pain intensity, personal care, lifting, reading, headaches, concentration, work, driving, sleeping, and recreation) graded from 0 (no activity limitations) to 5 (major activity limitations), which are added together, and transformed into percentages ( $0 \%$, no pain or difficulty; $100 \%$, highest score for pain and difficulty). NDI was completed in a questionnaire before the tests. To detect a minimal clinically important change, a NDI reduction of $7 \%$ is required (37). The NDI is considered a reliable and valid measurement of disability in patients with neck pain disorders (37). Levels of disability in WAD 6 months after the injury were defined by NDI scores from 0 to 100 : full recovery $\mathrm{NDI}<10$, mild to moderate disability 11 to 29 , ongoing moderate/severe pain and disability NDI > 30 (38).

\section{Adherence to exercise}

Data on adherence to exercise during the 12-week intervention period were collected from the physiotherapist-completed diaries in the NSE and NSEB groups and participant-completed exercise diaries in the PPA group. At 12 months' follow-up, the participants reported whether they had 
continued with the exercise program.

\section{Statistical analyses}

Analyses were performed using SPSS (version 24.0) statistical package. Descriptive statistics were analyzed with one-way analyses of variance (ANOVA) or the Kruskal-Wallis test for non-normally distributed data. For binary outcomes, the chi-square test was used. Drop-out analysis was performed using the Mann-Whitney $U$ test by comparing the baseline variables between drop-outs at 12 months and individuals who completed outcome measurements. The study sample size was based on the primary outcome (NDI) of the RCT (29) and calculation showed that 63 participants per group were required. To account for drop-outs, a total of 216 participants were recruited. Statistical significance was set at an a level of .05. The analysis was performed on an intention-to-treat basis, including all participants who completed each measurement.

Linear mixed model was used to analyze ventral and dorsal NME, AROM, grip strength and pain as dependent variables, taking into account time from intervention (4 levels: baseline, 3, 6 and 12 months) and intervention group (3 levels: NSE, NSEB and PPA). A first-order heterogeneous factor analysis was used, with time as repeated factor, group as fixed factor and sex as a covariate. Included in the model were individuals with baseline data and at least one more measurement. Three analyses were performed for the total AROM (values in degrees of flexion/extension, right/left lateral flexion and right/left rotation). NME was measured in seconds and grip strength value (in kilograms) was the mean value of right and left grip strength. NME data were strongly positively skewed and the measurements were Log10 transformed. AROM, grip strength and pain were normally distributed.

Cut-off for normative reference values for healthy individuals were as follows: ventral NME was set to $\geq 23 \mathrm{~s}$ for females and $\geq 56 \mathrm{~s}$ for males; dorsal NME $\geq 173 \mathrm{~s}$ for females and $\geq 157 \mathrm{~s}$ for males (33); AROM was set to $\geq 93^{\circ}$ to $\geq 110^{\circ}$ in flexion/extension, $\geq 49^{\circ}$ to $\geq 77^{\circ}$ in total lateral flexion, and $\geq 97^{\circ}$ to $\geq 135^{\circ}$ in total rotation (normative reference values for healthy individuals in both female and male subjects across a range of ages) (39); grip strength was set to $\geq 25 \mathrm{~kg}$ for females and $\geq 42 \mathrm{~kg}$ for males (40). The sub-group analyses for individuals below against in line with and above the reference values were evaluated with a non-parametric test, using median and inter-quartile ranges, between-group differences in NDI were analyzed using Kruskal-Wallis tests and post hoc comparisons were evaluated with the Mann-Whitney U test, when indicated.

\section{Results}

The test and questionnaires were completed by 160-185 participants (74-85\%) at the follow-up assessments (Fig. 1). Baseline characteristics were similar between groups, except that more females were included in the NSE group and the participants were generally younger compared with the PPA group (Table 1). There were no differences between drop-outs and those who completed the intervention regarding baseline measurements in NME, AROM, grip strength or pain during testing ( $p>.27$ ). Adherence to exercise during the 12-week intervention period was in the NSE and NSEB groups $70 \%$ and $71 \%$, and in the PPA group 49\%, $p=.07$. At 12 months' follow-up, $25 \%$ in NSE, $34 \%$ in NSEB and $42 \%$ in the PPA group reported they trained completely or almost completely according to their exercise program and $54 \%$ (NSE) respectively $35 \%$ (NSEB and PPA) trained to some extent $(p=.09)$. Of the total group $(n=216)$, individuals below the cut-off reference values in NME, AROM and grip strength had significantly higher $\mathrm{NDI}$ at baseline compared with those in line with or above the reference values: below the reference values, NDI median 34 to 38 (IQR, $26-46$ ), in line with or above the reference values, NDI median 26 to 30 (IQR, 18-38), p<.01. There were no differences between WAD grades II and III in the proportion of individuals below against in line with or above the reference values $(p>.15)$ except for grip strength where more individuals with WAD grade III (64\%) were below the reference values $(p=.05)$.

Results in neck muscle endurance, active range of motion, grip strength and pain during testing

Unadjusted data from the tests are shown in Table 2. In dorsal NME, there were significant between-group differences: both females and males improved in the NSE and NSEB groups compared to the PPA group $(F=3.6, p<.01)$. There were significant between-group and sex differences in ventral NME ( $F=5.1$ to $22.1, p<.01)$. Males in both the NSE and NSEB groups improved compared to the PPA group $(F=22.2, p<.01)$. There were no significant between-group differences for females $(F=0.2, p>.91)$, but females in the NSEB group improved from baseline to 12 months $(F=3.6, p$ $<.03)$. 
Table 2

Ventral and dorsal neck muscle endurance, cervical range of motion and grip strength for neck-specific exercise (NSE), neck-specific exercise with a behavioral approach (NSEB) and prescribed physical activity (PPA) groups.

\begin{tabular}{|c|c|c|c|c|}
\hline Variable & Period & NSE & NSEB & PPA \\
\hline \multicolumn{5}{|c|}{ Ventral NME } \\
\hline \multirow[t]{2}{*}{ Women } & Baseline & $14(9-30)[2-222]$ & $17(8-33)[2-162]$ & $24(13-48)[2-101]$ \\
\hline & 12 months & $23(11-40)[2-125]$ & $25(9-46)[3-114]$ & $23(7-57)[3-79]$ \\
\hline \multirow[t]{2}{*}{ Men } & Baseline & $59(22-91)[5-243]$ & $40(21-82)[5-175]$ & $21(9-64)[4-373]$ \\
\hline & 12 months & $67(42-143)[6-183]$ & $51(31-110)[10-258]$ & $25(13-65)[1-200]$ \\
\hline \multicolumn{5}{|c|}{ Dorsal NME } \\
\hline \multirow[t]{2}{*}{ Women } & Baseline & $33(18-79)[0-511]$ & $37(17-113)$ [2-660] & $46(19-174)[5-540]$ \\
\hline & 12 months & $89(34-176)[0-1860]$ & $74(37-155)[6-964]$ & $60(12-166)[4-450]$ \\
\hline \multirow[t]{2}{*}{ Men } & Baseline & $108(28-202)[10-421]$ & $66(32-153)[3-405]$ & $50(9-170)[3-347]$ \\
\hline & 12 months & $127(47-186)[1-382]$ & $166(60-292)[13-1305]$ & $56(27-122)[0-634]$ \\
\hline \multicolumn{5}{|l|}{ AROM } \\
\hline \multicolumn{5}{|c|}{ Flexion/extension } \\
\hline \multirow[t]{4}{*}{ Women } & Baseline & $95(26.2)[26-138]$ & $98(30)$ [34-152] & $99(26.1)$ [22-143] \\
\hline & 3 months & 102 (28.6) [18-147] & 102 (32.9) [20-158] & $98(25)[42-134]$ \\
\hline & 6 months & $101(28.3)[26-156]$ & $106(32)$ [24-172] & 99 (27.6) [26-132] \\
\hline & 12 months & 105 (26.4) [42-156] & $106(28.6)$ [28-155] & $94(29.4)[24-134]$ \\
\hline \multicolumn{5}{|l|}{ Men } \\
\hline & Baseline & $104(26)[49-150]$ & $92(24.4)[25-122]$ & $89(19.5)[50-130]$ \\
\hline & 3 months & $109(24.2[60-135]$ & $94(21.2)[47-124]$ & $88(25.4)[30-125]$ \\
\hline & 6 months & $113(26.5)$ [52-139] & $96(23.1)[20-135]$ & $92(25.6)[33-138]$ \\
\hline & 12 months & $110(24.8)[60-143]$ & $106(25.7)[60-143]$ & $94(27.4)[30-144]$ \\
\hline \multicolumn{5}{|c|}{ Lateral flexion } \\
\hline \multirow[t]{4}{*}{ Women } & Baseline & $66(18.1)$ [22-99] & $66(18.1)[32-108]$ & 70 (15.9) [20-96] \\
\hline & 3 months & $68(18.8)[18-110]$ & 70 (21.7) [24-128] & $67(18.8)[26-100]$ \\
\hline & 6 months & 69 (17.7) [28-100] & $71(20.3)[20-110]$ & 69 (18.6) [18-104] \\
\hline & 12 months & $70(19,1)[32-120]$ & $72(19.1)$ [24-115] & 65 (17.5) [30-95] \\
\hline \multirow[t]{4}{*}{ Men } & Baseline & 68 (15.2) [39-87] & $61(20.4)[8-92]$ & $61(17.4)[30-94]$ \\
\hline & 3 months & $74(23.8)[28-110]$ & 66 (20.6) [15-95] & 59 (16.8) [10-112] \\
\hline & 6 months & 73 (21.6) [32-108] & $66(20.0)$ [14-95] & $62(21.8)[10-112]$ \\
\hline & 12 months & $73(21.8)$ [36-114] & 69 (21.7) [20-104] & 60 (21.6) [18-136] \\
\hline \multicolumn{5}{|l|}{ Rotation } \\
\hline \multirow[t]{4}{*}{ Women } & Baseline & $114(26.4)[30-170]$ & $112(27.4)[50-162]$ & $114(25.4)[26-166]$ \\
\hline & 3 months & 118 (21.2) [40-147] & 118 (29.4) [22-172] & $107(30.4)[36-154]$ \\
\hline & 6 months & $116(23.0)[54-155]$ & $123(29.1)[22-172]$ & $110(24.5)[48-144)$ \\
\hline & 12 months & 120 (22.7) [28-158] & 121 (27.7) [40-176] & 109 (28.4) [50-154] \\
\hline
\end{tabular}

Values are presented as median and inter-quartile range (IQR) and [range] for neck muscle endurance values (NME) at baseline and 12 months. Active range of motion and grip strength are presented as mean, standard deviation (SD) and [range] at baseline, 3, 6 and 12 months.

NME, neck muscle endurance; AROM, active range of motion; NSE, neck-specific exercise; NSEB, neck-specific exercise with a behavioral intervention; PPA, prescription of physical activity 


\begin{tabular}{|c|c|c|c|c|}
\hline Variable & Period & NSE & NSEB & PPA \\
\hline \multirow[t]{4}{*}{ Men } & Baseline & 115 (26.0) [58-180] & 107 (31.3) [11-140] & 105 (25.5) [55-155] \\
\hline & 3 months & $118(27.1)$ [60-154] & 115 (23.3) [45-146] & 107 (26.7) [34-154] \\
\hline & 6 months & 119 (31.2) [32-164] & $111(28.4)[34-150]$ & $106(27.6)[34-146]$ \\
\hline & 12 months & $119(23.1)$ [74-150] & $117(24.6)[45-154)$ & $105(28.8)[32-150]$ \\
\hline \multicolumn{5}{|l|}{ Grip strenght } \\
\hline \multirow[t]{4}{*}{ Women } & Baseline & $22.6(6.4)[12-39]$ & $22.6(5.8)$ [9-43] & $23.1(7.1)[7-40]$ \\
\hline & 3 months & $22.3(5.8)[10-36]$ & $22.7(6.1)[4-40]$ & $22.2(8.1)[1-34]$ \\
\hline & 6 months & $23.5(6.5)[12-38]$ & $24.4(8.5)$ [10-59] & $23.6(7.3)[1-37]$ \\
\hline & 12 months & $24.9(6.2)[11-34]$ & $24.5(6.1)[4-42]$ & $22.0(8.4)$ [2-35] \\
\hline \multirow[t]{4}{*}{ Men } & Baseline & $40.7(10.5)[21-64]$ & $43.7(9.5)$ [30-59] & $40.4(12.6)[31-49]$ \\
\hline & 3 months & $42.2(10.1)[21-57]$ & 42.5 (10.6) [21-60] & $42.2(12.4)[11-66]$ \\
\hline & 6 months & $43.1(9.9)[19-60]$ & $46.6(10,8)[26-66]$ & $44.8(10.6)[21-63]$ \\
\hline & 12 months & 41.7 (10.4) [18-57] & $45.4(11.1)[26-62]$ & $44.5(13.2)[16-66]$ \\
\hline \multirow[t]{2}{*}{ VAS before test } & Baseline & $33(22.1)$ [0-88] & $33(25.1)$ [0-86] & $36(22.9)$ [0-91] \\
\hline & 12 months & $20(21.5)[0-77]$ & $26(23.4)[0-80]$ & $32(27.4)$ [0-92] \\
\hline \multirow[t]{2}{*}{ VAS after test } & Baseline & $40(23.8)$ [0-97] & $42(27.6)$ [0-95] & 45 (25.2) [0-93] \\
\hline & 12 months & $28(24.2)[0-88]$ & $33(27.8)[0-100]$ & $40(28.5)$ [0-91] \\
\hline \multicolumn{5}{|c|}{$\begin{array}{l}\text { Values are presented as median and inter-quartile range (IQR) and [range] for neck muscle endurance values (NME) at baseline and } 12 \text { months. } \\
\text { Active range of motion and grip strength are presented as mean, standard deviation (SD) and [range] at baseline, 3, } 6 \text { and } 12 \text { months. }\end{array}$} \\
\hline
\end{tabular}

There were significant between-group differences in AROM ( $F=5.9$ to $14.3, p<.01)$ : the NSE and NSEB groups improved compared with the PPA group in flexion/ extension, and rotation $(F=5.9, p<.01)$. Lateral flexion was improved in the NSE group compared with the PPA group $(F=10.2, p$ $<.01)$.

In grip strength, there were no significant between-group differences $(F=2.9, p<.05)$, but there were significant within-group differences over time ( $F$ $=2.9, p=.03)$. Females in all three exercise groups had improved grip strength $(p<.05)$.

There were significant between-group differences in pain both immediately before (decreased pain in the NSE group compared to the PPA group; $F=$ $4.2, p<.02$ ) and after the tests (decreased pain in both the NSE and NSEB groups compared to the PPA group; $F=16.3, p<.01$ ) at 12 months' follow up.

Change scores in self-reported disability (NDI) in individuals below or above the reference values for healthy individuals in neck muscle endurance, active range of motion and grip strength

At 12 months, NDI was improved in individuals both below and in line with or above the cut-off reference values for NME, AROM and grip strength (only in line with or above the cut-off for grip strength) in the NSE and/or the NSEB groups compared with the PPA group, (NSE - 3 to -7 , NSEB -2 to -11 ; PPA -4 to $8, p<.04)$ (Table 3$)$. There were no significant differences between the NSE and NSEB groups $(p>.07)$. In the PPA group, NDI increased (worsen disability) for individuals below the cut-off reference values in cervical flexion/extension and lateral flexion $(p<.05)$ from baseline to 12 months' follow-up. 
Table 3

Change score in Neck Disability Index (NDI \%) from baseline to 12 months' follow-up for individuals below and above the normative cut-off reference values for healthy individuals in neck muscle endurance, cervical range of motion and grip strength; differences are between NSE, NSEB and PPA groups.

\begin{tabular}{|c|c|c|c|c|c|c|c|c|c|c|c|c|}
\hline \multirow{3}{*}{ Variable } & \multirow{2}{*}{\multicolumn{2}{|c|}{ NSE }} & \multirow{2}{*}{\multicolumn{2}{|c|}{ NSEB }} & \multirow{2}{*}{\multicolumn{2}{|c|}{ PPA }} & \multicolumn{6}{|c|}{ P-value, between group differences } \\
\hline & & & & & & & \multicolumn{2}{|c|}{ NSE - PPA } & \multicolumn{2}{|c|}{ NSEB - PPA } & \multicolumn{2}{|c|}{ NSE - NSEB } \\
\hline & e normal & $\underset{\text { normal }}{\geq}$ & normal & $\underset{\text { normal }}{\geq}$ & normal & $\underset{\text { normal }}{\geq}$ & normal & $\underset{\text { normal }}{\geq}$ & normal & $\underset{\text { normal }}{\geq}$ & normal & $\underset{\text { normal }}{\geq}$ \\
\hline Ventral NME & $\begin{array}{l}-1 \\
(-11 \text { to } \\
8)\end{array}$ & $\begin{array}{l}-6 \\
(-18 \text { to } \\
0)\end{array}$ & $\begin{array}{l}-5(- \\
14 \text { to } \\
4)\end{array}$ & $\begin{array}{l}-11 \\
(-18 \text { to } \\
-5)\end{array}$ & $\begin{array}{l}4(-4 \text { to } \\
10)\end{array}$ & $\begin{array}{l}0(-8 \text { to } \\
4)^{\star}\end{array}$ & .12 & .03 & .03 & .003 & .40 & .48 \\
\hline Dorsal NME & $\begin{array}{l}-3(-12 \\
\text { to } 7)\end{array}$ & $\begin{array}{l}-9(-21 \\
\text { to }-5)\end{array}$ & $\begin{array}{l}-8(-15 \\
\text { to } 2)\end{array}$ & $\begin{array}{l}-8 \\
(-18 \text { to } \\
-4)\end{array}$ & $\begin{array}{l}3 \text { (-4 to } \\
10)\end{array}$ & $\begin{array}{l}-6(-8 \\
\text { to } 0)^{\star}\end{array}$ & .04 & .16 & .001 & .16 & .19 & .16 \\
\hline \multicolumn{13}{|l|}{ Range of motion } \\
\hline Flexion/extension & $\begin{array}{l}-3 \\
(-18 \text { to } \\
5)\end{array}$ & $\begin{array}{l}-6 \\
(-14 \text { to } \\
1)\end{array}$ & $\begin{array}{l}-2(-16 \\
\text { to } 6)\end{array}$ & $\begin{array}{l}-8 \\
(-18 \text { to } \\
-4)\end{array}$ & $\begin{array}{l}8 \text { (0 to } \\
10)\end{array}$ & $\begin{array}{l}0 \text { (-8 to } \\
3)^{\star}\end{array}$ & .02 & .13 & .02 & .004 & .83 & .14 \\
\hline Lateral flexion & $\begin{array}{l}0(-10 \\
\text { to } 10)\end{array}$ & $\begin{array}{l}-7 \\
(-18 \text { to } \\
-1)\end{array}$ & $\begin{array}{l}-6(-20 \\
\text { to } 6)\end{array}$ & $\begin{array}{l}-8(-17 \\
\text { to }-3)\end{array}$ & $\begin{array}{l}6(11 \\
\text { to } 6)\end{array}$ & $\begin{array}{l}0 \text { (-6 to } \\
6)^{\star}\end{array}$ & .07 & .01 & .07 & .001 & .07 & .61 \\
\hline Rotation & $\begin{array}{l}-4 \\
(-16 \text { to } \\
8)\end{array}$ & $\begin{array}{l}-6 \\
(-15 \text { to } \\
0)\end{array}$ & $\begin{array}{l}-4 \\
(-14 \text { to } \\
6)\end{array}$ & $\begin{array}{l}-8 \\
(-18 \text { to } \\
-4)\end{array}$ & $\begin{array}{l}2 \text { (0 to } \\
10)\end{array}$ & $\begin{array}{l}-4(-8 \\
\text { to } 6)\end{array}$ & .06 & .07 & .02 & .01 & .76 & .25 \\
\hline Grip strength & $\begin{array}{l}-2(-10 \\
\text { to } 8)\end{array}$ & $\begin{array}{l}-6(-18 \\
\text { to } 0)\end{array}$ & $\begin{array}{l}-6(-20 \\
\text { to } 6)\end{array}$ & $\begin{array}{l}-8(-16 \\
\text { to }-2)\end{array}$ & $\begin{array}{l}2(-4 \text { to } \\
10)\end{array}$ & $\begin{array}{l}0 \text { (-8 to } \\
\text { 7) }\end{array}$ & .08 & .02 & .08 & .003 & .08 & .75 \\
\hline \multicolumn{13}{|c|}{$\begin{array}{l}\text { NSE, neck-specific exercise; NSEB, neck-specific exercise with behavioral intervention; PPA, prescription of physical activity; NME, neck muscle } \\
\text { endurance; Values are presented as median and inter-quartile range (IQR). }\end{array}$} \\
\hline \multicolumn{13}{|c|}{$\begin{array}{l}\text { Cut-off normative reference values for healthy individuals; ventral NME } \geq 23 \mathrm{~s} \text { for females and } \geq 56 \mathrm{~s} \text { for males, dorsal NME } \geq 173 \mathrm{~s} \text { for } \\
\text { females and } \geq 157 \mathrm{~s} \text { for males, active cervical range of motion; flexion/extension } \geq 98^{\circ} \text {, total lateral flexion (right and left) } \geq 43^{\circ} \text {, total rotation } \\
\text { (right and left) } \geq 109^{\circ} \text {, grip strength } \geq 25 \mathrm{~kg} \text { for females and } \geq 42 \mathrm{~kg} \text { for males. }\end{array}$} \\
\hline
\end{tabular}

There were significant differences in the NSE, NSEB and PPA groups at 12 months' follow-up between individuals below against above the cut-off reference values for NME and AROM. For grip strength, there were differences in the NSE and PPA groups (Table 4, p<.05). In the NSE and NSEB groups, NDI was significantly improved at 12 months' follow-up for individuals above the reference value (NDI, median (IQR); 22 (7-29) to 6 (0-22) compared with individuals below the reference value (NDI; $36(23-49)$ to $23(7-14)(p<.05)$. In the PPA group, individuals below the reference values for NME, AROM and grip strength had increased disability (NDI; 48 (32-52) to 42 (28-48) at 12 months' follow-up compared with those above the reference values (NDI; $30(18-40)$ to 20 (14-28) (Table 4, p<.05). 
Table 4

Neck Disability Index (NDI) at baseline and 12 months' follow-up in the NSE, NSEB and PPA groups, number and percentage of individuals below and in line or above cut-offs for normative reference values in neck muscle endurance, cervical range of motion and grip strength.

\begin{tabular}{|c|c|c|c|c|c|c|}
\hline \multirow{3}{*}{$\begin{array}{l}\text { Variable } \\
\text { NSE group }\end{array}$} & \multirow[t]{2}{*}{ Baseline } & & & \multicolumn{3}{|l|}{12 months } \\
\hline & & \multicolumn{2}{|c|}{ NDI, median (IQR) } & \multicolumn{3}{|c|}{ NDI (median (IQR) } \\
\hline & $\mathbf{n}$ & $<$ normal & $\geq$ normal & $\mathbf{n}$ & $<$ normal & $\geq$ normal \\
\hline Ventral NME & $28(36 \%)^{*}$ & $34(24-44)$ & $28(22-38)^{\star}$ & $27(52 \%)^{\star}$ & $30(19-46)$ & $18(12-24)^{\star}$ \\
\hline Dorsal NME & $12(16 \%)$ & $30(24-42)$ & $26(22-35)$ & $14(27 \%)$ & $26(18-44)$ & $18(2-20)^{\star}$ \\
\hline \multicolumn{7}{|l|}{ Range of motion } \\
\hline Flexion/extension & $35(46 \%)^{*}$ & $34(24-33)$ & $30(22-40)$ & $35(63 \%)^{*}$ & $30(20-48)$ & $18(7-29) *$ \\
\hline Lateral flexion & $42(55 \%)$ & $36(27-47)$ & $28(22-32)^{\star}$ & $36(66 \%)$ & $36(23-49)$ & $18(11-26)^{\star}$ \\
\hline Rotation & 37 (49\%) & $34(24-42)$ & $28(23-39)$ & $31(56 \%)$ & $30(18-48)$ & $18(7-26)^{\star}$ \\
\hline Grip strength & $30(39 \%)^{*}$ & $34(28-43)$ & $26(22-36)$ & $29(57 \%)^{\star}$ & $36(21-46)$ & $18(6-24)^{\star}$ \\
\hline NSEB group & $\mathbf{n}$ & $<$ normal & $\geq$ normal & $\mathrm{n}$ & $<$ normal & $\geq$ normal \\
\hline Ventral NME & $28(36 \%)^{*}$ & $38(28-46)$ & $27(20-34)^{\star}$ & $30(53 \%)^{\star}$ & $27(17-44)$ & $22(7-29)$ \\
\hline Dorsal NME & $14(20 \%)$ & $36(24-44)$ & $24(15-34) \star$ & $15(27 \%)$ & $28(18-38)$ & $6(0-22) *$ \\
\hline \multicolumn{7}{|l|}{ Range of motion } \\
\hline Flexion/extension & $44(62 \%)$ & $42(26-52)$ & $30(22-36)^{*}$ & 40 (67\%) & $30(15-48)$ & $20(10-30)^{*}$ \\
\hline Lateral flexion & $40(56 \%)$ & $38(26-50)$ & $30(22-38)^{\star}$ & $39(66 \%)$ & $32(12-44)$ & $20(11-28)^{*}$ \\
\hline Rotation & $32(45 \%)^{*}$ & $30(24-44)$ & $34(22-39)$ & $37(63 \%)^{\star}$ & $34(20-46)$ & $20(9-28)^{\star}$ \\
\hline Grip strength & $29(41 \%)^{*}$ & $35(22-34)$ & $30(23-38)$ & $35(61 \%)^{*}$ & $23(7-41)$ & $22(12-32)$ \\
\hline PPA group & $\mathbf{n}$ & $<$ normal & $\geq$ normal & $\mathbf{n}$ & $<$ normal & $\geq$ normal \\
\hline Ventral NME & $28(53 \%)$ & $36(28-47)$ & $28(18-39) *$ & $20(41 \%)$ & $44(31-52)$ & $24(12-34)^{*}$ \\
\hline Dorsal NME & $17(25 \%)$ & $37(28-46)$ & $24(16-30) *$ & $10(21 \%)$ & $42(28-48)$ & $20(14-28)^{*}$ \\
\hline \multicolumn{7}{|l|}{ Range of motion } \\
\hline Flexion/extension & $38(55 \%)$ & $36(28-48)$ & $30(19-40) *$ & $26(52 \%)$ & $48(32-52)$ & $28(14-40)^{*}$ \\
\hline Lateral flexion & $45(62 \%)$ & $38(32-50)$ & $30(19-41)^{*}$ & $31(62 \%)$ & $48(31-56)$ & $31(16-42)^{\star}$ \\
\hline Rotation & $30(43 \%)$ & $36(28-48)$ & $28(19-38)^{\star}$ & $22(44 \%)$ & $42(32-52)$ & $28(11-41)^{\star}$ \\
\hline Grip strength & $35(51 \%)$ & $37(26-46)$ & $32(20-38)$ & $26(56 \%)$ & $44(25-52)$ & $30(18-40) *$ \\
\hline \multicolumn{7}{|c|}{$\begin{array}{l}\text { NDI; Neck Disability Index, median and inter-quartile range (IQR), NME; neck muscle endurance, NSE; neck-specific exercise, NSEB; neck-specific } \\
\text { exercise with behavioral intervention, PPA; prescription of physical activity }\end{array}$} \\
\hline \multicolumn{7}{|c|}{$\begin{array}{l}n(\%) \text {; number and percentage of individuals above }(\geq=\text { on/over) the cut-off (normative reference values for healthy individuals) in neck muscle } \\
\text { endurance (NME), active range of motion (AROM) and grip strength at baseline and at } 12 \text { months' follow-up, * }=p<0.05 \text {, significant differences } \\
\text { between baseline and } 12 \text { months' follow-up for number of individuals above ( } \geq=\text { on/over) the cut-off for normative reference value in NME, } \\
\text { AROM and grip strength. }\end{array}$} \\
\hline \multicolumn{7}{|c|}{$\begin{array}{l}\text { Cut-off normative reference values in NME, AROM and grip strength; ventral NME } \geq 23 \mathrm{~s} \text { for females and } \geq 56 \mathrm{~s} \text { for males, dorsal NME } \geq 173 \mathrm{~s} \\
\text { for females and } \geq 157 \mathrm{~s} \text { for males, cervical range of motion; flexion/extension } \geq 98^{\circ} \text {, total lateral flexion (right and left) } \geq 43^{\circ} \text {, total rotation } \\
\text { (right and left) } \geq 109^{\circ} \text {, grip strength } \geq 25 \mathrm{~kg} \text { for females and } \geq 42 \mathrm{~kg} \text { for males. }\end{array}$} \\
\hline
\end{tabular}

\section{Discussion}

This study showed that three months of neck-specific exercise (NSE and NSEB) results in greater improvements in NME, AROM and pain intensity after testing in chronic WAD compared to prescribed physical activity (PPA) and these improvements were maintained at 12 months' follow-up. In the subgroup analyses, significant or closed to significant improvements in NDI from baseline to 12 months were found in the NSE and/or the NSEB groups compared with the PPA group for individuals both below and above the cut-off reference values for NME, AROM and grip strength. Despite 
that individuals in the present study were above the cut-off for normative reference values at baseline for NME, AROM and grip strength, they reported moderate to severe disability (38) before they started the exercise interventions. The increased disability at 12 months for those in the PPA group below cut-off reference values indicates the importance of enhancing neck function with neck-specific exercise as the best alternative. However, many individuals in the NSE and NSEB groups did not reach normal values (33-48\%) in ventral NME, AROM and grip strength, and only $27 \%$ reached normal values in dorsal NME at 12 months' follow-up, indicating that more effort is needed to improve exercise interventions in chronic WAD.

As has been found previously (26), NME was improved and pain intensity during testing was decreased in the NSE and NSEB groups after neckspecific exercises at six months' follow-up. The present study showed that the results of NME were maintained at 12 months' follow-up and that AROM showed significantly greater improvement during the same time period in the NSE and NSEB groups compared with the PPA group. The results suggest that three months of neck-specific exercise with the recommendation to continue exercise was a better alternative than PPA. Pain intensity was measured immediately before and after the neck muscle endurance test. At 12 months' follow-up, pain intensity during testing as well as NME were improved. Reduced load-bearing capacity of the neck has earlier been reported by Kristjansson et al. (48) in females with chronic WAD, suggesting that enhanced endurance of neck muscles is important. The results of the present study indicate that neck-specific exercise improved load-bearing capacity of the cervical spine and that these results were maintained at 12 months' follow-up. The results also showed that individuals in the PPA group below the cut-off reference values in NME, AROM and grip strength reported a higher score in disability at 12 months' follow-up (NDI $\geq 42$ ). This is well over the level defined by Ritche et al (38) for ongoing moderate/severe pain and disability (NDI > 30) indicating that general exercises lead to worsening disability for these individuals.

As presented previously (26), there were no differences between groups for females in ventral NME at 3 and 6 months follow-up and the results at 12 months' follow-up were the same, suggesting that general exercises such as those undertaken in the PPA group can be equally effective as neckspecific exercises. However, the neck-specific exercise program (NSE and NSEB) was directed at improving the endurance of the deep flexor, rotator, and extensor muscles which showed reduced pain intensity after the tests that lasted to 12 month's follow-up, indicating a better strategy for improved neck-related function and disability. To enhance endurance in ventral neck muscles a program of increasing intensity over a longer period or other exercises may be needed. Previous studies have reported altered function between deep and superficial neck muscles in chronic WAD (41, 42), and have found that the deep ventral neck muscles were elongated during arm elevation (41) suggesting altered inter-segmental activation in the deep ventral neck muscles which may decrease cervical spine stability. Peterson et al. (42) reported that the interplay between the deep dorsal neck muscles was weaker in females with WAD which may decrease muscular support in the maintenance of a stable cervical spine. Moreover, activation of the deep ventral neck muscles were delayed in chronic neck pain and exercise targeted to improve neuromuscular control of the deep muscles decreased pain and improved the activation of the muscles (43). The NME tests used in the present study cannot distinguish between deep and superficial muscles but it can be speculated that the neck-specific exercise used in the NSE and NSEB groups trained the deep neck muscles, resulting in decreased pain and improved neck muscle function which is altered in chronic WAD $(4,6,7)$.

Many individuals in the present study showed decreased NME, AROM and grip strength compared to reported normative reference values both at baseline and 12 months' follow-up $(33,39,40)$. There are to our knowledge no guidelines for the level of endurance that is needed to perform daily activities and it seems reasonable to assume that the variance between individuals is high due to their work situations and daily activities. It seems also reasonable to assume that an important goal in rehabilitation after whiplash injury could be to improve NME, AROM and grip strength to reach the cut-off for normative reference values, but there is no guarantee that normative values indicate no pain or disability in chronic WAD. In the present study, individuals reported moderate to severe disability despite normative values in NME, AROM and grip strength at baseline. For individuals above the cut-off reference values neck-specific exercises were significantly more effective in improving disability at 12 months' followup (NSEB improved in all values except for dorsal NME; NSE improved in 3 values) compared to the PPA group. The results indicate that improvement in persistent disability after whiplash injury can occur if exercise interventions are directed at the neck muscles, and that more general exercise interventions, such as in the PPA group worsened disability for individuals below the cut-off reference values.

Neck-specific exercise seems to have the possibility to improve AROM. The main goal with the exercise program was initially to activate the deep neck muscles, minimize the contraction of superficial muscles and to increase neck muscle endurance. The deep neck muscles are supposed to maintain postural control due to their close attachment to the vertebrae and their unique capacity to contribute to control of intersegmental motion $(44,45)$. After initially deep activation exercises, progressive isometric endurance training of the neck muscles was introduced with only one concentric/eccentric resistance exercise, in cervical neck rotation. Despite that, AROM improved which may be a result of improved muscle function and decreased pain and that individuals could move their head more in daily life.

In other studies, psychological factors, such as fear-avoidance beliefs and pain catastrophizing, have been reported to be related to pain and disability in chronic WAD $(46,47)$; fear of movement was the strongest predictor for engagement in activities and pain acceptance (48). The behavioral approach added to the neck-specific exercise in the NSEB group was expected to enhance the benefits of neck-specific exercise by reducing fear of movement. However, there were no significant differences between the NSE and NSEB groups in any of the outcomes indicating that neck-specific exercise was the most important component to improve neck function and decrease pain after testing. The individuals in the present study scored low in fear of movement, catastrophizing and depression/anxiety at baseline (49), indicating that psychological factors may not have been a major concern.

Page $11 / 15$ 
Grip strength was slightly improved in the three exercise groups at 12 months. The participants in the three groups were encouraged to continue with general aerobic and strength exercise two to three times a week after the 12 weeks intervention. In the NSE and NSEB groups,

recommendations were given to continue with neck-specific exercise. Two studies have reported associations between low grip strength and disability and morbidity $(18,20)$. In the present study, including participants with WAD grade III with neurological deficits and pain in the arm, daily neck- and arm pain may result in low grip strength and therefore lead to lower physical activity. The results suggest that further progress in exercise programs for patients with chronic WAD are important, to improve self-reported disability and neck related function.

\section{Conclusion}

Individuals with chronic WAD randomized to three months of neck-specific exercise (NSE) and NSE with a behavioral approach (NSEB) maintained significantly greater improvements in neck-related clinical function at 12 months' follow-up compared with individuals randomized to prescribed physical activity (PPA). There were no significant differences between the NSE and NSEB groups. The results indicate that improvement in persistent moderate to severe disability and neck related clinical function after whiplash injury can occur if exercise interventions are directed to the neck muscles, as was the case in the NSE and NSEB groups. Greater improvements in disability were seen among individuals in line with or above the normative cut-off reference values for healthy individuals in neck muscle endurance, active cervical range of motion and grip strength, indicating that improved neck-related clinical function is important in chronic WAD. In the PPA group which did not have neck-specific exercises, increased disability was seen for individuals below the cut-off reference values.

\section{Declarations}

\section{Ethics approval and consent to participate}

The study was conducted in accordance with the Declaration of Helsinki and was approved by the Regional Ethics Committee of Linköping University, Sweden (Dnr: 2010/188-31, Dnr: 2011/262-32). All participants received verbal and written information about the study before allocation. Written consent was sent to the research group. The participants also gave verbal consent before allocation. All investigations were conducted in conformity with ethical principles.

\section{Consent for publication}

Not applicable

\section{Availability of data and materials}

The datasets used and analysed during the current study are available from the corresponding author on reasonable request.

\section{Competing interests}

The authors declare that they have no financial or non-financial competing interests.

\section{Funding}

This study was financially supported by funding from by the Swedish government in cooperation with the Swedish Social Insurance Agency through the REHSAM foundation, the Swedish Research Council, Centre for Clinical Research Sörmland at Uppsala University Sweden, UppsalaÖrebro Regional Research Council Sweden, the Medical Research Council of Southeast Sweden (FORSS).

\section{Authors' contributions}

GP and MLL participated in the recruitment and data collection. GP drafting the manuskript. GP, AP and MLLcontributed to the study design and conception, and revision of the manuscript. All authors read and approved the final manuscript.

\section{Acknowledgments}

The authors thank all participants in this study, including WAD participants, physiotherapists, and staff involved in this study.

\section{References}

1. Carroll LJ, Holm LW, Hogg-Johnson S, Cote P, Cassidy JD, Haldeman S, et al. Course and prognostic factors for neck pain in whiplashassociated disorders (WAD): results of the Bone and Joint Decade 2000-2010 Task Force on Neck Pain and Its Associated Disorders. J Manipulative Physiol Ther. 2009;32(2 Suppl):97-107.

2. Styrke J, Sojka P, Björnstig U, Stålnacke B-M. Symptoms, disabilities, and life satisfaction five years after whiplash injuries. Scandinavian Journal of Pain. 2014;5(4):229-36. 
3. Berglund A, Alfredsson L, Jensen I, Cassidy JD, Nygren A. The association between exposure to a rear-end collision and future health complaints. J Clin Epidemiol. 2001;54(8):851-6.

4. Woodhouse A, Vasseljen O. Altered motor control patterns in whiplash and chronic neck pain. BMC Musculoskelet Disord. $2008 ; 9: 90$.

5. Woodhouse A, Liljeback P, Vasseljen O. Reduced head steadiness in whiplash compared with non-traumatic neck pain. Journal of rehabilitation medicine: official journal of the UEMS European Board of Physical Rehabilitation Medicine. 2010;42(1):35-41.

6. Jull G, Kristjansson E, Dall'Alba P. Impairment in the cervical flexors: a comparison of whiplash and insidious onset neck pain patients. Man Ther. 2004;9(2):89-94.

7. Schomacher J, Farina D, Lindstroem R, Falla D. Chronic trauma-induced neck pain impairs the neural control of the deep semispinalis cervicis muscle. Clin Neurophysiol. 2012;123(7):1403-8.

8. Prushansky T, Gepstein R, Gordon C, Dvir Z. Cervical muscles weakness in chronic whiplash patients. Clinical biomechanics. 2005;20(8):794-8.

9. Sullivan MJ, Lariviere C, Simmonds M. Activity-related summation of pain and functional disability in patients with whiplash injuries. Pain. 2010;151(2):440-6.

10. Sandlund J, Roijezon U, Bjorklund M, Djupsjobacka M. Acuity of goal-directed arm movements to visible targets in chronic neck pain. J Rehabil Med. 2008;40(5):366-74.

11. See KS, Treleaven J. Identifying upper limb disability in patients with persistent whiplash. Man Ther. 2015;20(3):487-93.

12. Ritchie C, Sterling M. Recovery Pathways and Prognosis After Whiplash Injury. J Orthop Sports Phys Ther. 2016;46(10):851-61.

13. Hamberg-van Reenen HH, Ariens GA, Blatter BM, Twisk JW, van Mechelen W, Bongers PM. Physical capacity in relation to low back, neck, or shoulder pain in a working population. Occup Environ Med. 2006;63(6):371-7.

14. van der Meer S, Reneman MF, Verhoeven J, van der Palen J. Relationship between self-reported disability and functional capacity in patients with whiplash associated disorder. J Occup Rehabil. 2014;24(3):419-24.

15. Liew BXW, Scutari M, Peolsson A, Peterson G, Ludvigsson ML, Falla D. Investigating the Causal Mechanisms of Symptom Recovery in Chronic Whiplash-associated Disorders Using Bayesian Networks. Clin J Pain. 2019;35(8):647-55.

16. Shugg JA, Jackson CD, Dickey JP. Cervical spine rotation and range of motion: pilot measurements during driving. Traffic Inj Prev. 2011;12(1):82-7.

17. Garcia-Hermoso A, Cavero-Redondo I, Ramirez-Velez R, Ruiz JR, Ortega FB, Lee DC, et al. Muscular Strength as a Predictor of All-Cause Mortality in an Apparently Healthy Population: A Systematic Review and Meta-Analysis of Data From Approximately 2 Million Men and Women. Arch Phys Med Rehabil. 2018;99(10):2100-13. e5.

18. Leong DP, Teo KK, Rangarajan S, Lopez-Jaramillo P, Avezum A Jr, Orlandini A, et al. Prognostic value of grip strength: findings from the Prospective Urban Rural Epidemiology (PURE) study. Lancet. 2015;386(9990):266-73.

19. Sasaki H, Kasagi F, Yamada M, Fujita S. Grip strength predicts cause-specific mortality in middle-aged and elderly persons. Am J Med. 2007;120(4):337-42.

20. Henriksson $\mathrm{H}$, Henriksson $\mathrm{P}$, Tynelius $\mathrm{P}$, Ortega FB. Muscular weakness in adolescence is associated with disability 30 years later: a populationbased cohort study of 1.2 million men. Br J Sports Med. 2018.

21. Rebbeck T. The Role of Exercise and Patient Education in the Noninvasive Management of Whiplash. J Orthop Sports Phys Ther. 2017;47(7):481-91.

22. Michaleff ZA, Maher CG, Lin CW, Rebbeck T, Jull G, Latimer J, et al. Comprehensive physiotherapy exercise programme or advice for chronic whiplash (PROMISE): a pragmatic randomised controlled trial. Lancet. 2014;384(9938):133-41.

23. Vikne J, Oedegaard A, Laerum E, Ihlebaek C, Kirkesola G. A randomized study of new sling exercise treatment vs traditional physiotherapy for patients with chronic whiplash-associated disorders with unsettled compensation claims. Journal of rehabilitation medicine: official journal of the UEMS European Board of Physical Rehabilitation Medicine. 2007;39(3):252-9.

24. Stewart MJ, Maher CG, Refshauge KM, Herbert RD, Bogduk N, Nicholas M. Randomized controlled trial of exercise for chronic whiplashassociated disorders. Pain. 2007;128(1-2):59-68.

25. Ludvigsson ML, Peterson G, Dedering A, Peolsson A. One- and two-year follow-up of a randomized trial of neck-specific exercise with or without a behavioural approach compared with prescription of physical activity in chronic whiplash disorder. J Rehabil Med. 2016;48(1):56-64.

26. Peterson GE, Landen Ludvigsson MH, O'Leary SP, Dedering AM, Wallman T, Jonsson MI, et al. The Effect of 3 Different Exercise Approaches on Neck Muscle Endurance, Kinesiophobia, Exercise Compliance, and Patient Satisfaction in Chronic Whiplash. J Manipulative Physiol Ther. 2015;38(7):465-76. e4.

27. Schulz KF, Altman DG, Moher D, Group C. CONSORT 2010 statement: updated guidelines for reporting parallel group randomised trials. PLoS Med. 2010;7(3):e1000251.

28. Spitzer WO, Skovron ML, Salmi LR, Cassidy JD, Duranceau J, Suissa S, et al. Scientific monograph of the Quebec Task Force on WhiplashAssociated Disorders: redefining "whiplash" and its management. Spine. 1995;20(8 Suppl):1S-73S. 
29. Peolsson A, Landen Ludvigsson M, Overmeer T, Dedering A, Bernfort L, Johansson G, et al. Effects of neck-specific exercise with or without a behavioural approach in addition to prescribed physical activity for individuals with chronic whiplash-associated disorders: a prospective randomised study. BMC Musculoskelet Disord. 2013;14(1):311.

30. Aletras AH, Ding S, Balaban RS, Wen H. DENSE: displacement encoding with stimulated echoes in cardiac functional MRI. J Magn Reson. 1999;137(1):247-52.

31. Glanz K, Rimer BK, Viswanath K. Health behavior and health education: theory, research and practice. San Francisco: Jossey-Bass; 2008.

32. Edmondston SJ, Wallumrod ME, Macleid F, Kvamme LS, Joebges S, Brabham GC. Reliability of isometric muscle endurance tests in subjects with postural neck pain. J Manipulative Physiol Ther. 2008;31(5):348-54.

33. Peolsson A, Almkvist C, Dahlberg C, Lindqvist S, Pettersson S. Age- and sex-specific reference values of a test of neck muscle endurance. J Manipulative Physiol Ther. 2007;30(3):171-7.

34. Williams MA, Williamson E, Gates S, Cooke MW. Reproducibility of the cervical range of motion (CROM) device for individuals with sub-acute whiplash associated disorders. Eur Spine J. 2012;21(5):872-8.

35. Peolsson A, Hedlund R, Oberg B. Intra- and inter-tester reliability and reference values for hand strength. J Rehabil Med. 2001;33(1):36-41.

36. Carlsson AM. Assessment of chronic pain. I. Aspects of the reliability and validity of the visual analogue scale. Pain. 1983;16(1):87-101.

37. Vernon H. The Neck Disability Index: state-of-the-art, 1991-2008. J Manipulative Physiol Ther. 2008;31(7):491-502.

38. Ritchie C, Hendrikz J, Jull G, Elliott J, Sterling M. External validation of a clinical prediction rule to predict full recovery and ongoing moderate/severe disability following acute whiplash injury. J Orthop Sports Phys Ther. 2015;45(4):242-50.

39. Youdas JW, Garrett TR, Suman VJ, Bogard CL, Hallman HO, Carey JR. Normal range of motion of the cervical spine: an initial goniometric study. Phys Ther. 1992;72(11):770-80.

40. Leong DP, Teo KK, Rangarajan S, Kutty VR, Lanas F, Hui C, et al. Reference ranges of handgrip strength from 125,462 healthy adults in 21 countries: a prospective urban rural epidemiologic (PURE) study. J Cachexia Sarcopenia Muscle. 2016;7(5):535-46.

41. Peterson G, Nilsson D, Trygg J, Falla D, Dedering A, Wallman T, et al. Novel insights into the interplay between ventral neck muscles in individuals with whiplash-associated disorders. Sci Rep. 2015;5:15289.

42. Peterson G, Nilsson D, Peterson S, Dedering A, Trygg J, Wallman T, et al. Changes in Dorsal Neck Muscle Function in Individuals with Chronic Whiplash-Associated Disorders: A Real-Time Ultrasound Case-Control Study. Ultrasound Med Biol. 2016;42(5):1090-102.

43. Falla D, Jull G, Hodges PW. Feedforward activity of the cervical flexor muscles during voluntary arm movements is delayed in chronic neck pain. Exp Brain Res. 2004;157(1):43-8.

44. Mayoux-Benhamou MA, Revel M, Vallee C, Roudier R, Barbet JP, Bargy F. Longus colli has a postural function on cervical curvature. Surg Radiol Anat. 1994;16(4):367-71.

45. Panjabi MM. The stabilizing system of the spine. Part I. Function, dysfunction, adaptation, and enhancement. J Spinal Disord. 1992;5(4):3839. discussion 97.

46. Vernon H, Guerriero R, Kavanaugh S, Soave D, Puhl A. Self-rated disability, fear-avoidance beliefs, nonorganic pain behaviors are important mediators of ranges of active motion in chronic whiplash patients. Disabil Rehabil. 2013;35(23):1954-60.

47. Chiarotto A, Fortunato S, Falla D. Predictors of outcome following a short multimodal rehabilitation program for patients with whiplash associated disorders. Eur J Phys Rehabil Med. 2015;51(2):133-41.

48. Soderlund A, Lofgren M, Stalnacke BM. Predictors before and after multimodal rehabilitation for pain acceptance and engagement in activities at a 1-year follow-up for patients with whiplash-associated disorders (WAD)-a study based on the Swedish Quality Registry for Pain Rehabilitation (SQRP). Spine J. 2018;18(8):1475-82.

49. Overmeer T, Peterson G, Landen Ludvigsson M, Peolsson A. The effect of neck-specific exercise with or without a behavioral approach on psychological factors in chronic whiplash-associated disorders: A randomized controlled trial with a 2-year follow-up. Medicine. 2016;95(34):e4430.

\section{Figures}




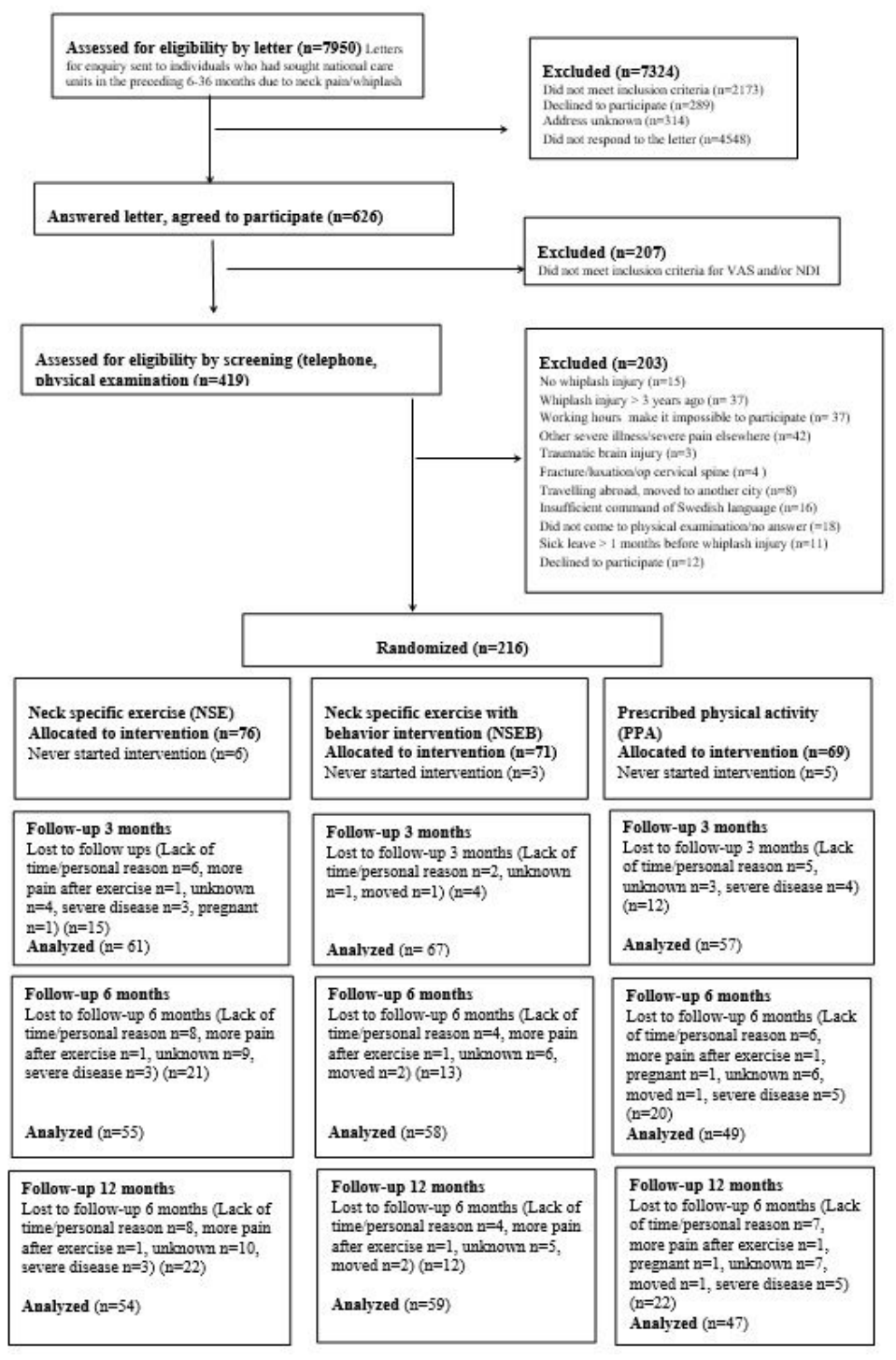

Figure 1

Flow diagram of participants in the study

\section{Supplementary Files}

This is a list of supplementary files associated with this preprint. Click to download.

- CONSORT2010ChecklistMSWord200605.pdf 